\title{
Blogs: A qualitative investigation into an instructor and undergraduate students' experiences
}

\author{
Erkan Tekinarslan \\ Abant Izzet Baysal University
}

\begin{abstract}
This study reports on the experiences of an instructor and an undergraduate class who used blogs in their teaching and learning environment at Abant Izzet Baysal University, Turkey. Qualitative data were collected from observation of students' activities when working on blogs in the classroom, analyses of students' blog documents on the web, and interviews with 42 students. Most students reflected that blogs are user friendly and convenient tools for publishing and sharing studies. Moreover, blog implementations contributed positively to students' information searching and writing skills, despite the limited opportunities that many students had for Internet access outside the university. However, students' ignorance regarding copyright issues and their tendency to copy information from online sources and paste it into their blogs was a common problem.
\end{abstract}

\section{Introduction}

Web 2.0 technologies such as blogs (weblogs) and wikis have become popular social networking tools all over the world. Specifically, a blog is web publishing software which allows users to create and edit the content of a web page with a minimum of technical expertise (Holtz, 2006). A typical blog site consists of "a single page of entries which are accessible by the public, arranged in reverse chronological order, containing hyperlinks to other blogs or web sites, and written by a single author" (Guenther, 2005, p. 53).

Although most of blogs on the Internet are personal and journalistic, there has been increasing interest in applying blogs in education in recent years (Godwin-Jones, 2003). According to the related literature (e.g. Achterman, 2006; Godwin-Jones, 2003; Ray, 2006), blogs have the potential to be used as supplementary communication means, collaborative tools, and instructional resources in educational environments. In addition, blogs can be used to improve students' writing skills, as discussed in prior literature (Godwin-Jones, 2003; Hernández-Ramos, 2004; Johnson, 2004; Huffaker, 2005).

Finally, related literature (e.g. Winder, 2006; Williams \& Jacobs, 2004) shows that blogs have been used by an increasing number of individuals in variety of fields such as business and education. Business people have been quick to benefit from blogs, followed by educational institutions (e.g. universities), libraries and research facilities (Winder, 2006; Williams \& Jacobs, 2004). The purpose of this study is to report on experiences of an instructor and his undergraduate students in the Faculty of Education at Abant Izzet Baysal University, Turkey, who applied blogs in their teaching-learning environment. 


\section{Internet penetration in Turkey}

Internet penetration in Turkey $(23 \%)$ is notably lower than the penetration in developed European Union countries (50\%). Although Turkey has the demographics of a developing country with GDP/capita of around US $\$ 5,000$, Internet penetration in Turkey is catching up rapidly, with the introduction of a number of campaigns to drive Internet penetration in education and other sectors (Business Monitor International, 2008). In general, there have been more attempts to integrate the Internet into Turkish higher education than into primary and secondary education (Usun, 2003).

\section{Statement of the problem}

According to the literature about blogs (e.g. Achterman, 2006; Godwin-Jones, 2003; Williams \& Jacobs, 2004; Ray, 2006) these easy to use web publishing tools have considerable potential for communication and educational purposes. However, most studies about blogs in the literature were conducted in English speaking countries (e.g. Australia, USA) which have higher Internet penetration rates than Turkey. Besides, blog experiences of Turkish instructors and undergraduates have not been investigated sufficiently. Therefore, this study concentrates on blog experiences of a Turkish instructor and his undergraduate students in two groups, who encounter lower Internet penetration and lesser opportunities to access online information sources outside the campus. In particular, this study reports on the teaching and learning experiences they had during educational uses of blogs in Turkish, and the advantages and disadvantages of using these new technologies in an educational environment in Turkey.

\section{Structure of the course and learning outcomes}

Blog experiences of the instructor and his two groups of undergraduate students were investigated in a two credit hours elective course named Computer Usage II. The course was given during 2006-2007 Spring semester in the Faculty of Education at Abant Izzet Baysal University, Turkey. Students were taught basic applications in database management in MS Access during the first four weeks of the course, followed by basic web design applications in MS FrontPage for four weeks. Finally, Web 2.0 technologies including blogs and wikis were introduced during the last four weeks of the course. Students were given a midterm and a final examination. Their final grades were based on the following topics and weightings: 20\% midterm exam about Access, 20\% final exam about FrontPage, and 60\% assignments, comprising Access (20\%), FrontPage (20\%) and blog (20\%) assignments.

In regard to wikis, the instructor expected to achieve learning outcomes related mainly to online collaboration of students. However, the instructor used externally hosted wiki systems for which authentication and tracking features were administered by the external provider. Therefore, he was not able to effectively monitor the online or wiki collaboration of students as it was planned. As a result, this paper reports only on experiences of the instructor and his undergraduate students with blogs.

The instructor expected to achieve the following learning outcomes concerning blogs at the end of the course:

1. Students will be able to create, edit, and publish their own blog pages. 
2. Students will have improved their information search and literature review skills while developing contents for blogs.

3. Students will have improved their academic writing skills (e.g. referencing, paraphrasing) while reporting literature review results through blogs.

Before blog activities, students worked on web designs in FrontPage and gained basic technical skills in designing web pages. However, the instructor noticed that students were focusing mostly on technical applications of web design, rather than upon writing and developing content for their web pages. Moreover, they could not publish their web pages after designing in FrontPage since most students could not find a server with free web hosting. Therefore, the instructor thought that it would be easy to get the students to concentrate on writing and developing blog content rather than focusing on technical side of web design, as blogs are relatively easy to use tools with free web hosting services. Furthermore, the instructor thought that access to blogs by many people may have a motivating effect towards writing better essays, as suggested by Godwin-Jones (2003).

\section{Methods}

\section{Participants}

The participants in the study were an instructor and undergraduate students $(\mathrm{n}=55)$ who took the elective Computer Usage II in two groups $(n=27$ and $n=28)$. The students (25 female, 30 male) were third and fourth year students in the department of elementary education. Moreover, 42 students (20 female, 22 male) from the same cohort voluntarily completed an interview form to provide additional data about their blog experiences.

\section{Data collection}

A qualitative research approach, called fieldwork, formed the methodological framework of this investigation (Bogdan and Biklen, 1992). The fieldwork approach incorporated a number of data gathering techniques including interviews, document analysis, and participant observation to analyse experiences of undergraduate Faculty of Education students with blogs.

\section{Participant observation}

The researcher was the instructor for the course in which undergraduate students in two groups were taught educational applications of various software (MS Access, MS FrontPage) as well as Web 2.0 technologies including blogs. After the students learned how to create blogs and examined various previous blog applications on the web, they were required to build up their own blogs with educational content. The researcher recorded notes about students' blog activities. Moreover, he noted his notable experiences and observations while the students were working on their blogs in the computer lab.

\section{Document analysis}

The documents analysed in this study comprised blog documents created by students and their email attachments concerning their blogs. Students emailed the instructor about the contents and URL addresses of their blog pages. The email attachments and students' blog contents were documented for analysis. 


\section{Interview}

An interview form containing six questions was administered at the end of the semester to ascertain views and thoughts of the students about blogs. Students were not obliged to provide personal information on the interview form. A total of 42 students participated voluntarily in the interview process. They submitted their interview forms electronically by floppy disk or USB disk $(n=9)$ at the end of the last course or by email attachments $(n=33)$ within two weeks after the end of the course. Students answered the following questions in the interview form:

1. What do you think about the easiness and difficulties of publishing blog pages on the web?

2. Do you think writing in a blog environment contributes in any way to your writing skills?

3. Do you think preparing blog content contribute in any way to your research skills?

4. What are the advantages of submitting assignments through blogs in comparison with the traditional methods?

5. What are the disadvantages of submitting assignments through blogs in comparison with the traditional methods?

6. What are the other advantages and disadvantages of blogs in educational environments?

Also, students $(\mathrm{n}=14)$ were asked additional questions by email when more detailed information was needed to better understand their blog experiences. Moreover, triangulation of data from multi sources (i.e. participant observation, document analysis, interviews with the students) was applied to achieve reliability and better results (Denzin, 1989).

\section{Data analyses procedures}

The data were analysed during the 2007 summer semester. Initially, the researcher printed out the collected digital data (i.e. blog documents, email attachments, observations, interview forms) and assigned pseudonyms to the interview forms of the participants. Then, a category construction approach comprising organisation of the data sources, reduction of the text, and generation of conceptual categories by coding units of the data, was applied in order to analyse the printed data (Bogdan \& Biklen, 1992). Specifically, when reading the data the researcher assigned coding categories as codes (e.g. teaching experiences, learning experiences, advantages, disadvantages, etc) to the units of data. Unrelated data were reduced or eliminated during the coding process. After that, the coded data were placed in folders under the appropriate categories (Bogdan \& Biklen, 1992). The findings were reported based on the categories generated during the analysis of data. The coursework and interview activities were in Turkish and translations were made by the author into English as necessary.

\section{Results}

\section{Teaching experiences with blogs}

Teaching students how to create a blog is an easy and straightforward activity. A blog is created in three steps: 1 . Creating an account, 2. Naming the blog, and 3. Choosing a template. The teacher showed the students these three steps on the Turkish version of Blogger (see Figure 1) through a data projector in the computer laboratory. 


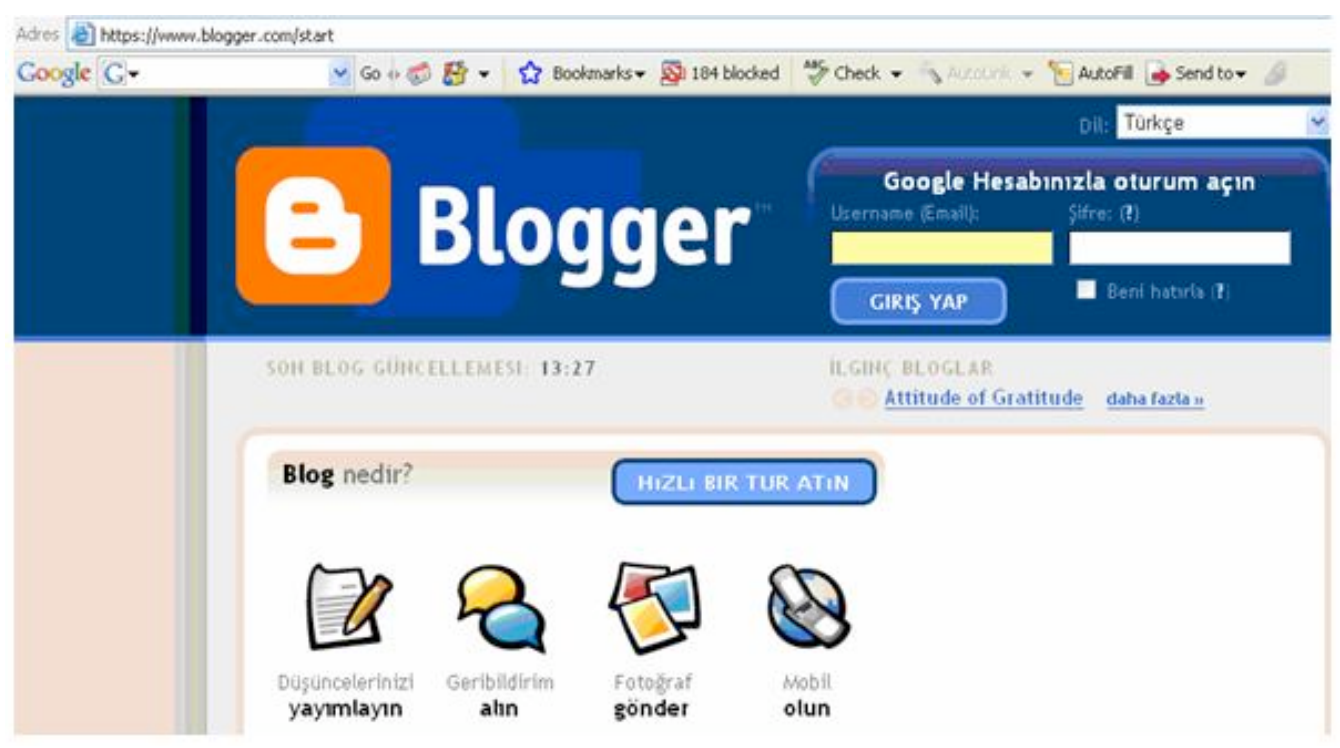

Figure 1: Home page of Blogger in Turkish

When the teacher was publishing his personal blog the students observed and took notes. A few students asked the instructor to repeat the steps. When students were ready to work on their blogs, the teacher asked them to create their personal blogs in three steps and then write small entries. All students were able to create and publish their blogs without facing any major difficulty. Only a few students sought help from the instructor in opening an account and changing an existing template. After the students learned how to create blogs, the teacher showed them how to edit an exiting blog content. Only a few students needed help while they were replacing or removing existing visuals (e.g. pictures).

In the next meeting with the students in the computer laboratory, the instructor showed the students his existing blog and various educational blog applications on the web in order to provide some ideas regarding educational uses of the blogs. After the students mastered their blog skills (i.e. publishing, editing) and examined a number of educational blog applications on the web, they were required to create similar educational blogs. The students created their blogs in Turkish as most were not proficient enough in English. However, students were encouraged to resort to and benefit from information in English, since English is likely to be the predominant language used in information found through Internet search engines. Specifically, the students were asked to undertake the following four tasks:

1. Conduct a literature review by benefiting from at least four printed and online resources (e.g. books, journals, electronic journals, web sites, etc) to develop the content for your blog.

2. Choose a topic related to education or educational technology as the content of your blog.

3. Report the literature review results with at least 500 words through blogs with appropriate citations and references.

4. Submit your blog content with its URL address in two weeks. 
However, most (about 30 out 55) of the students responded that they did not have adequate skills in any citation styles. Therefore, the instructor provided citation examples for both electronic and written resources, based on the Publication Manual of the American Psychological Association (APA), 5th edition.

Nearly half of the students (21 out of 55) could not decide on specific topics in education and they sought help from the instructor about topics and contents of their blogs. The instructor suggested topics related to field of education and educational technology, such as computers or the Internet in elementary schools. After they decided on the topics, many students (17 out of 55) complained that they were not able to find sufficient useful online information related to their topics. Therefore, they sought help from the instructor when searching the online resources. The instructor noticed that these students were just typing a phrase or some words when searching information through search engines without applying advanced search techniques. The instructor showed them how to search and locate online information by using advanced searches in Google [http://www.google.com.tr/] and Google Scholar [http:// scholar.google.com.tr] with command menus in Turkish.

The students emailed the instructor with the content of their blogs and URLs after they created their blogs. Many students (24 out of 55) consulted only online resources and less than half ( 21 out of 55) cited both online and written resources when developing contents of their blogs. Most students preferred to use online and written information in Turkish. However, their limited citation and paraphrasing skills were major problems during the content development process. For instance, many students did not appropriately cite the online $(n=20)$ and written resources $(n=12)$ in accord with APA citation styles. The students had problems in the citing of both English and Turkish information sources. However, students who used online information in English were more likely to have problems with improperly cited references. After searching the titles and subtitles of the students' blog contents through search engines, the instructor realised that considerable number of students $(n=11)$ copied and pasted some amount of text from the online resources without appropriately paraphrasing. Furthermore, by using search engines, the instructor found that four students plagiarised by copying and pasting from the online resources, without paraphrasing or citing any references. Most students corrected their inappropriately cited references and removed their unparaphrased and plagiarised texts from their blogs after receiving feedback and proper examples from the instructor.

Upon being asked for a reason, the students replied that their inappropriate or unethical actions in their blog contents (e.g. uncited references, unparaphrased text, plagiarised texts) occurred as a result of their limited skills in citing and paraphrasing, as well as their lack of awareness about terms of use for online information sources. Besides, these students noted that creating content for their blogs helped them to improve their skills in online research, citation and paraphrasing, though they had difficulties at the beginning.

\section{Learning experiences with blogs}

The students did not have any significant difficulty when learning how to create their blog pages on the web. Moreover, nearly all interviewed students (39 out of 42) thought that publishing a blog page on the web is an easy and straightforward activity when they were asked about its easiness and difficulties. Besides, a considerable number of the students $(n=8)$ reflected that publishing a blog page does not take so 
much time when compared with publishing a web page through other web composers. For instance, one of the students, Ebru (names are pseudonyms) stated that:

\begin{abstract}
Blogs are user friendly programs and publishing a web-blog is a quite simple activity that takes place through three steps. In particular, use of existing templates helps a lot when developing a blog page. Otherwise, it would have been an extremely difficult activity. I spent just 15 minutes for creating a blog page in Blogger, including publication part on the web. However, I remember it took me almost two days just to design a web page in FrontPage.
\end{abstract}

Although publishing a blog page on the web was a quite simple task, content development for blogs was a difficult and sophisticated task for many students. The instructor's observations and document analyses indicated that the students had difficulty in deciding on a topic for their blogs $(n=21)$, searching the related online literature $(n=17)$, paraphrasing the literature $(n=11)$, citing online $(n=20)$ and written resources $(n=12)$. An interviewed student, Tekin, expressed his opinions in regard to publishing a blog page and the content as follows:

Creating a blog page was a very smooth and straightforward activity for me. I set up a
frame for my blog page in 20 minutes by using existing frames in the Blogger.
However, filling out the frame, I mean developing the content, was a more detailed
and sophisticated job. I had to decide on a content topic, review the literature,
paraphrase and cite the literature, and find various visuals related to the blog content.
These things required a lot of work and took at least a week. But, I improved my
literature review, paraphrasing and referencing skills while I was doing these works
for my blog.

\title{
Advantages of blogs
}

Most interviewed students reflected more than one advantages of blogs in educational environments. The advantages of blogs for students were found to be their contribution to students' writing, information searching and literature review skills, as well as their easy to use features, and convenience for submitting assignments electronically.

The interviewed students reflected that writing in blog environments contributed to their writing skills in terms of organisation $(n=5)$, paraphrasing $(n=9)$, and referencing or citation $(n=28)$. One of the interviewees, Elif, stated her opinions as follows:

Preparing blog content contributed greatly to my writing skills. I just focused on the content writing since I didn't have to worry about web design and publishing skills in blogs. So, I feel my writing skills related to organisation, paraphrasing, referencing have been improved by writing the blog content.

Furthermore, another interviewed student, Derya, expressed her experiences about the contribution of blogs to her writing skills as follows:

I think content writing for blogs contributed to my citation skills in APA style. I didn't know how to cite an author and resource in the body text and references section. But, I can do it now based on APA style.

Moreover, nearly half of the interviewed students (18 out of 42) stated that preparing blog content contributed to their information searching and literature review skills. For instance, Ebru, noted that: 
I needed to look for the related literature before writing the content of the blogs. I think my searching skills improved a lot when I was looking for sources and related literature for the content of blogs.

Another interviewee, Caner, stated his opinion about the contribution of blogs to his information searching skills as follows:

Blogging made a great contribution to my online information searching skills. I learned how to find formal online information by using search engines when I was searching information for the content of my blog.

Many students (23 out of 42) thought that blogs were more convenient and cost effective tools for disseminating information than traditional methods such as using folders and printed copies. For instance, Cemre stated that:

Many times I had to print out the assignments, put them in a folder and go to campus in order to submit my assignment. This traditional way of submitting assignments is time consuming, expensive and requires too much work in comparison to electronic way of submitting assignments such as blogs and email.

When asked about other advantages of blogs, some students $(n=5)$ did not write any other advantages. However, many students perceived other advantages of blogs as easy to use features $(n=21)$, existing templates $(n=7)$, free web page hosting $(n=5)$, and encouragement to take greater responsibility for preparing better assignments $(n=4)$. Emre gave the following opinions regarding the advantages of the blogs:

Blogs are very easy to use programs, there is nothing confusing in creating and editing a blog page. Also, I did not have to worry about where to publish my blog page, because it is published in two minutes without any charge after creating the blog page. I just needed to approve the publication. However, I had to look for a free server or space to upload and publish my other web pages, which were designed via web composers. Besides, I can add a content and edit my blog page in the Blogger whenever I want. I just need a user name and password to edit the blog page and add a new content. Also, I do not have to upload entire blog page and folders again after I edit some parts. However, when I want to edit and remove some parts in my website other than Blogger it takes more time and I have to upload many things again.

A few students (4 out of 42 ) reported that submitting assignments through blog pages encouraged them to assume greater responsibility for preparing better assignments, as they are viewable to everyone all over the world. For instance, one of the interviewees, Ebru, stated that, "Publishing my assignments on the web was exciting and motivating for me because they could be viewable by everyone who has access to the Internet". Ersin noted that "I had to be more careful in my blog assignments since everyone in addition to my classmates and teacher could see my works on the web".

\section{Disadvantages of blogs}

The most common disadvantage of blogs was related to students' limited opportunities to access the Internet outside the campus. A considerable number of students $(n=22)$ complained that electronic or digital assignments such as blogs are not convenient for students who do not have enough chance to access to a computer outside the course in the computer laboratory. For example Melek stated that:

I don't have a personal computer at home and I don't have a chance to access a computer outside of the campus. Also, the computer labs are available within limited 
hours when I am at school. Therefore, I have to go to an Internet café to work on my assignments, but it's expensive for me.

Furthermore, according to a few students $(n=4)$, blogs are not sufficient to develop more sophisticated web sites, and some other programs (e.g. Flash, Dreamweaver) are needed to add more advanced applications such as animation and interactivity. One of the students, Taner, complained that:

Blogs are handy tools but they are insufficient to develop more complex and dynamic web sites. For example, when I want to develop and add an animation or counter for visitors, I need to use other software such as Flash and FrontPage.

\section{Discussion and conclusions}

The purpose of this study was to report on the experiences of an instructor and his undergraduate class who constructed blogs in their teaching-learning environment at Abant Izzet Baysal University, Turkey. Analyses of qualitative data indicated that blogs are quite easy to use tools for students to publish and share their studies with others. Similar to the findings of previous studies (e.g., Hernández-Ramos, 2004; Williams \& Jacobs, 2004), most students were able to set up and publish their blogs without facing any significant difficulty related to technical issues. However, the students had notable difficulties in developing and writing the content of their blogs at the beginning. Moreover, the instructor realised that some students plagiarised by copying and pasting from the online resources without paraphrasing and without citing any references when creating the content of their blogs. According to the students, their inappropriate and unethical actions (e.g., uncited references, unparaphrased text) occurred because of their limited citation skills and unawareness about terms of use for online information sources. These findings suggest that all students should be warned about terms of use and copyright issues before writing content for blogs, to avoid unethical and inappropriate behaviors such as plagiarism.

The biggest disadvantage of use of blogs for about half of the Turkish students was related to their limited opportunities to access computers with Internet connection outside of the campus. However, despite the students' difficulties in searching the literature, paraphrasing, citing online and written resources at the beginning, and despite their limited opportunities to access computers, most interviewed students agreed that blogging helped them to improve their skills in information searching, literature reviewing and writing. According to the interviewed students, blogging contributed to their writing skills in terms of organising, paraphrasing, citing or referencing, similar to the findings of related literature (e.g., Johnson, 2004; Huffaker, 2005; Hernández-Ramos 2004). Therefore, based on the findings of this study and related literature, it can be stated that blogs can be effective tools for students who want to practise and advance their skills in writing. Another advantage of blogging was its contribution to the students' information searching and literature reviewing skills when creating the content. This finding is consistent with the prior literature (e.g. Williams \& Jacobs, 2004; Embrey, 2002) which suggest that blogs can be used to build information search and retrieval skills.

In general, blogs are relatively user friendly tools. In this study, blogs with easy to use features were quite helpful in getting the students to concentrate on information searching, literature review and writing activities rather than on technical aspects of web publishing. The students did not seek any significant help about technical aspects 
of blogging. However, many students sought help and feedback about their information searching, literature review and writing activities. Thus, their skills in these areas improved when writing and developing content for blogs. The students' skills in information searching, literature review and writing could also have been improved if they had been trained and required to use search engines for literature review, and if they had submitted traditional essay type assignments. However, the findings of this study suggest that blogs can be used as alternative tools to improve students' skills in online searching, literature reviewing and writing.

In addition, as discussed in a prior study (Ray, 2006), blogs are more convenient and cost effective tools for students in disseminating information than traditional methods such as using folders and printed copies. Easy to use features with existing templates and free web hosting were considered other advantages of blogs by the students, similar to the findings of related literature (e.g. Hernández-Ramos, 2004; Embrey, 2002). As discussed in a prior study (Godwin-Jones, 2003), another advantage of blogging in this study was its encouragement for students to accept greater responsibility for preparing better assignments, as the blog pages are viewable to many people. The consistency between the findings of this study and prior related literature suggest that use of blogs in educational environments has common advantages for students in different societies.

In conclusion, the consistency between the findings of this study and related literature suggest that blogs, as easy to use web publishing tools, can be used to promote writing skills of students in different societies. Students can improve their information searching and literature review skills while developing content for blogs. However, students should be warned about terms of use of online information and copyright issues before starting their content writing for blogs, to limit the problems of plagiarism and inappropriate actions.

\section{References}

Achterman, D. (2006). Making connections with blogs and wikis. California School Library Association Journal, 30(1), 29-31.

Business Monitor International (2008). The Turkey Information Technology Report 2008. [viewed 17 June 2008] http:/ / www.businessmonitor.com/it/turkey.html

Bogdan, R. \& Biklen, S. K. (1992). Qualitative research for education (2nd ed.). Needham Heights, MA: Allyn and Bacon.

Denzin, N. K. (1989). The research act: A theoretical introduction to sociological methods (3rd ed). Englewood Cliffs, NJ: Prentice Hall, Inc.

Embrey, T. R. (2002). You blog, we blog: A guide to how teacher librarians can use weblogs to build communication and research skills. Teacher Librarian, 30(2), 7-9. [verified 16 July 2008] http: / / www.teacherlibrarian.com/tlmag/v_30/v_30_2_feature.html

Godwin-Jones, B. (2003). Emerging technologies. Blogs and wikis: Environments for on-line collaboration. Language Learning $\mathcal{E}$ Technology, 7(2), 12-16. [viewed 8 Sept 2007] http: / /lt.msu.edu/vol7num2/emerging/

Guenther, K. (2005). Socializing your web site with wikis, twikis, and blogs. Online, 29(6). [viewed 10 Sept 2007] http:/ / www.infotoday.com/online/nov05/index.shtml 
Hernández-Ramos, P. (2004). Web logs and online discussions as tools to promote reflective practice. The Journal of Interactive Online Learning, 3(1). [viewed 6 Sept 2007] http: / / www.ncolr.org/jiol/issues/PDF/3.1.4.pdf

Holtz, S. (2006). Communicating in the world of Web 2.0. Communication World, 23(3), 24-27.

Huffaker, D. (2005). The educated blogger: Using weblogs to promote literacy in the classroom. AACE Journal, 13(2), 91-98.

Johnson, A. (2004). Creating a writing course utilizing class and student blogs. The Internet TESL Journal, 10(8). [verified 16 July 2008]. http:/ / iteslj.org/Techniques/Johnson-Blogs/

Ray, J. (2006). Welcome to the Blogosphere: The educational use of blogs. Kappa Delta Pi Record, Summer 2006, 175-177.

Usun, S. (2003). Educational uses of Internet in the world and Turkey: A comparative review. Turkish Online Journal of Distance Education, 4(3). [viewed 17 June 2008] http: / / tojde.anadolu.edu.tr/tojde11/index.htm

Winder, D. (2006). Online tools: Blogs and wikis. Information World Review, 229, 28-31. [verified 17 Jul 2008] http: / / www.itweek.co.uk/information-world-review/ features/2168443/ onlinetools-blogs-wikis

Williams, J. B. \& Jacobs, J. (2004). Exploring the use of blogs as learning spaces in the higher education sector. Australasian Journal of Educational Technology, 20(2), 232-247. http: / / www.ascilite.org.au/ajet/ajet20/ williams.html

Erkan Tekinarslan, Assistant Professor, Department of Computer Education and Technology, Faculty of Education, Abant Izzet Baysal University, 14280, Bolu, Turkey. Email: tekinarslan_e@ibu.edu.tr 